\title{
Assessing the adoption and impact of genomics research at the Canadian Forest Service
}

\author{
by Emily S. Hope ${ }^{1 *}$, Debby C. Barsi² and Daniel W. McKenney ${ }^{1}$
}

\begin{abstract}
:
The outcomes and impacts of government scientific research are difficult to evaluate, yet there is a growing demand for quantification of these impacts. Forest and forestry-related research is no exception. We adapted an impact assessment methodology for the evaluation of eleven ongoing forestry-related genomics projects within the Canadian Forest Service. The assessment made use of two tools, a Desktop Analysis and a more comprehensive Project Review survey. Results of the assessments indicate that much of the research contributes to the fundamental knowledge of Canadian forests, but also produces short-term technological benefits, including enhanced methodologies for the protection of Canadian forests from invasive species. A full report is available at: https://cfs.nrcan.gc.ca/publications?id=38253 (English) and https://cfs.nrcan.gc.ca/publications?id=38254 (French).
\end{abstract}

Keywords: adoption and impact; forest genomics; scientific research outputs

\section{RÉSUMÉ}

Bien qu'on cherche de plus en plus à connaître les résultats et l'effet de la recherche effectuée par les gouvernements, il demeure difficile de mesurer ses effets. La recherche dans le domaine forestier ne fait pas exception à la règle. Nous nous sommes inspirés d'une méthodologie d’étude d'impacts pour évaluer onze projets de génomique forestière en cours au Service canadien des Forêts. Nous avons utilisé deux techniques pour réaliser cette évaluation, soit une analyse par ordinateur et une étude exhaustive des revues de projets. Cette évaluation montre qu'une grande partie des travaux de recherche permet de mieux connaître les forêts canadiennes et a également des retombées technologiques à court terme comme de meilleures méthodes pour protéger les forêts canadiennes contre les espèces envahissantes. On peut lire le texte intégral du rapport aux adresses suivantes : https://cfs.nrcan.gc.ca/publications?id=38253 (anglais) et https://cfs.nrcan.gc.ca/publications?id=38254 (Français).

Mots-clés : adoption et impact; génomique forestière; résultats de la recherche forestière

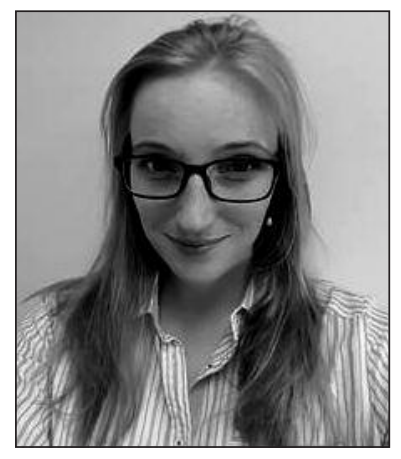

Emily S. Hope

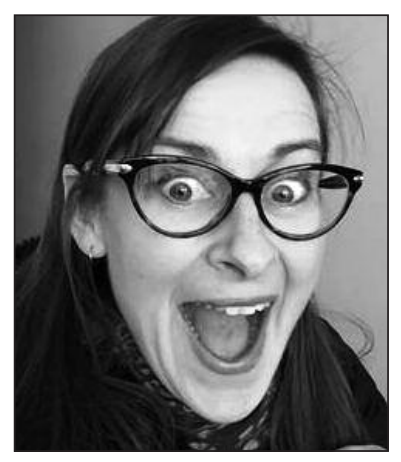

Debby C. Barsi

\section{Introduction}

Government investments in science are under scrutiny to demonstrate impact. "Deliverology", defined as a focus on results and delivery, is the new mantra within the Canadian Government (Senate of Canada 2016). Forest and forestryrelated research is no exception. In fact, this pressure has existed for some time in Canada and even internationally

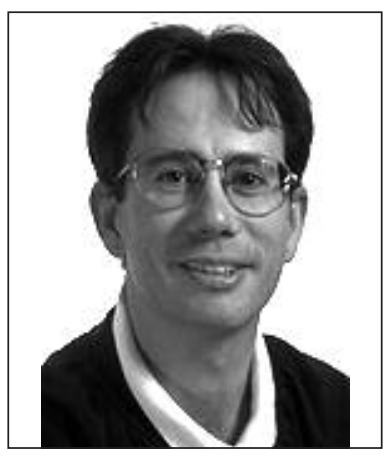

Daniel. W. McKenney
("Prove the worth of basic research" 2016). The longterm, broad-scale and public good nature of many types of research in forestry make it particularly challenging to quantify impacts and welfare changes. Despite the challenges, assessments of the adoption and impact of forestry-related research are increasingly required for the continued funding of government research programs.

Genomics is a science that looks at all of an organism's genetic material, its DNA, in order to understand how the organism functions and interacts within its environment. The resulting knowledge and data can be used to help answer a wide range of questions regarding species identification, distributions and productivity (Porth et al. 2015). For example, in the forestry context, genomics tools can be used in tree

\footnotetext{
${ }^{1}$ Great Lakes Forestry Centre, Canadian Forest Service, Natural Resources Canada, Sault Ste. Marie, Ontario, Canada, P6A 2E5; * corresponding author: Emily.hope@Canada.ca

${ }^{2}$ Canadian Forest Service, Natural Resources Canada, Ottawa, Ontario, Canada, K1A 0E4; current affiliation: Agriculture and Agri-Food Canada, Ottawa, ON, K1A 0C5
} 
improvement to help choose or select trees and significantly speed up breeding programs for traits of interest (e.g., wood properties, growth, pest resistance) (Isik 2014). In the context of alien invasive species, genomics tools may be used to help identify species and their origin; this information can then be used to guide international trade phytosanitary regulations, including quarantine decisions.

The Canadian Forest Service (CFS), part of Natural Resources Canada, has been involved with genomics-related research through the federal Genomics Research and Development Initiative (GRDI) for over 18 years. The Initiative was established to build genomics capacity within federal departments and agencies and support innovation and evidencebased regulatory, policy, and resource management decisions. The CFS, through the GRDI, has supported over 60 forestryrelated projects with investments amounting to approximately \$30 million since 1999. Furthermore, the Government of Canada, through Genome Canada, has also invested significant resources into genomics-related forestry research by supporting genomics science in Canadian universities (https://www.genomecanada.ca/en). Over the years, CFS scientists have built strong collaborative relationships with academic peers working together on both GRDI and Genome Canada-funded projects. We undertook a preliminary analysis of the potential adoption and impact of eleven currently ongoing GRDI projects at the CFS (see Table 1).

\section{Approach}

Assessing scientific research impacts is not trivial. The task itself requires significant investment and an understanding of how societal level impacts come about. Because research outputs are still being produced by the GRDI projects, we assessed anticipated adoption and impact with a 'pathways to change' framework. This framework is based on the extensive research evaluation efforts by the Australian Centre for International Agricultural Research (ACIAR). In addition to funding research investments, ACIAR invests heavily in the assessment of impacts and has accumulated over 34 years of experience conducting project evaluations. It uses evaluations to help define priorities, support future research, and provide

Table 1. Project titles and key project outputs for the eleven GRDI projects examined

Project Title Project Outputs Examined

Development of metagenomic and bioinformatic tools to facilitate processing of insect trap captures

Tools for enhanced molecular detection of Asian Gypsy Moth (AGM) and identification of their geographic origins

Ecogenomics of the spruce budworm (SBW)
- New and quicker method of identifying beetles

- Cost comparison between traditional and genomic trap capture identification approaches

- Method to identify the geographic origin of AGM populations

\section{in Ontario}

Accelerating the discovery of insect volatile attractant $\quad$ - New and quicker method to identify compounds for insect lure development molecules with genomics

Developing the next generation biosurveillance tools for tracking and preventing forest pest invasions

Applied genomics for tree breeding (GAPP) and new applications

Development of a molecular method to detect living Phytophthora spp. of phytosanitary concern in wood

Genomics-assisted tree breeding for improving remediation of disturbed forest ecosystems (White Pine Blister Rust - WPBR)
An early detection tool for emerald ash borer (EAB) and ash resource protection

Innovative land reclamation approaches following oil sands mining: a phytoremediation approach based on tree-soil microbiome interactions

Developing molecular and environmental genomic approaches for microbial and invertebrate communities to assess ecosystem integrity in forest management
- New method to detect and monitor select pests using genomics

- Portable detection system for specific pathogens

- Unique models for end users to identify optimal tree stock

- User marketing strategy to encourage further adoption of developed models

- Methods for differentiating between living and dead Phytophthora spp.

- Application of genomic tool to test the efficacy of novel phytosanitation wood treatments

- Method to screen and select molecular markers for resistance to WPBR in four five-needle pine species

- Diagnostic methods to distinguish among ash species

- Ash genes that respond to EAB attacks

- EAB compounds that trigger a response in ash

- Methods of monitoring tree-soil microbe interactions towards the reclamation of oil sands sites

- Characterization of the best populus species for land reclamation of disturbed sites

- Method for identifying microbe/invertebrate profiles to assess the sustainability of forest management practises

- Profiles of microbe and invertebrates under differing forest management practices 


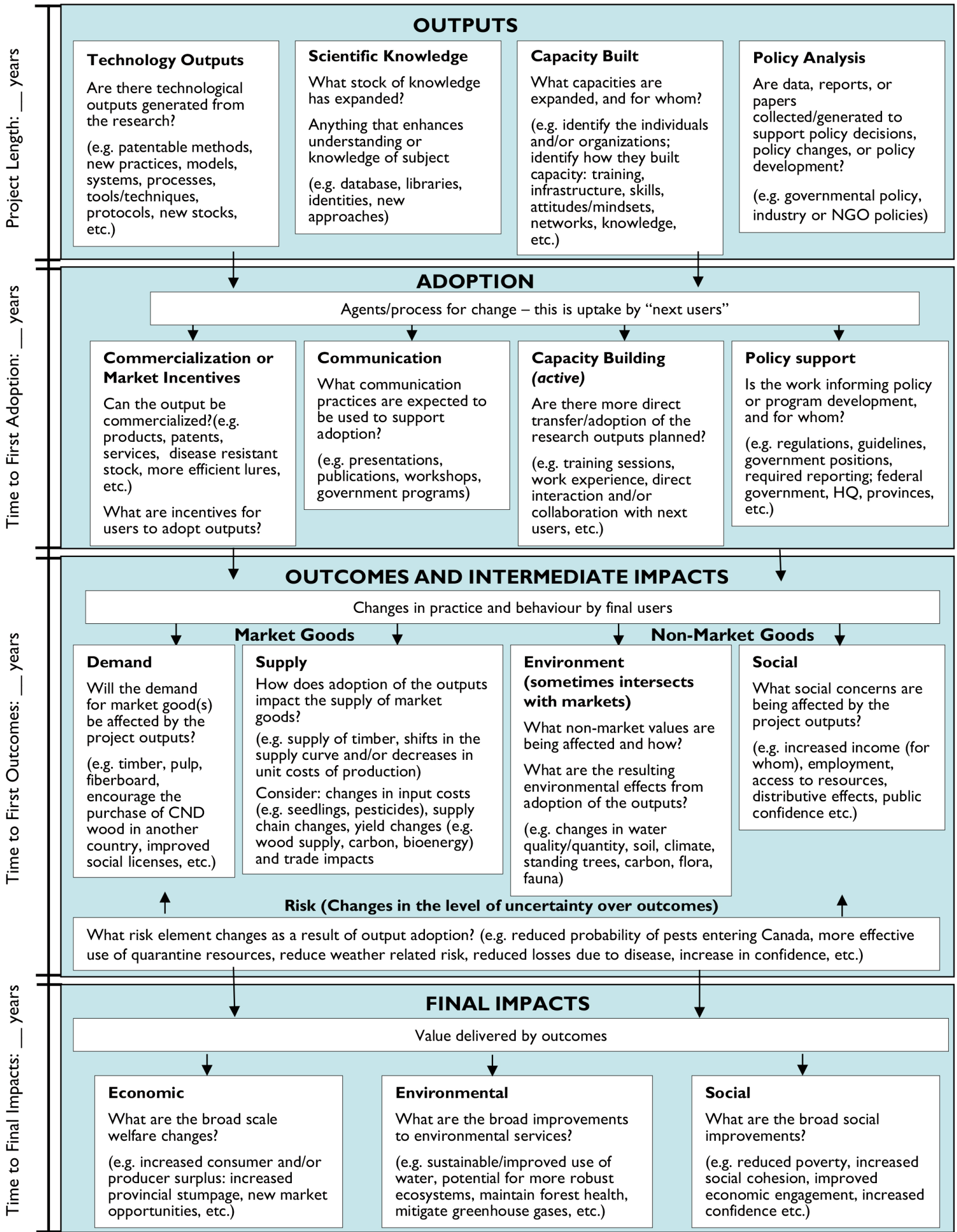

Fig. 1. The Desktop template used to assess GRDI project outputs. Each field is populated with questions and considerations designed to guide the interviewer and project researcher when filling in the template (adapted from Davis et al. 2008, found in Hope et al. 2017). 
accountability to the Australian public (Bartlett 2016). ACIAR's adoption and impact assessment work arguably represents one of the most concentrated efforts worldwide to practically assess the impacts of scientific research in the natural resources sector.

Our approach made use of two tools adapted from ACIAR:

1) A Desktop Analysis: a one-page infographic used to showcase the expected path between research project outputs and final impacts. It categorizes research deliverables into four major themes and then outlines the adoption of the outputs by intended users, the expected near-term impacts, and ultimately the nature of anticipated changes in aggregate social, economic and environmental conditions. Importantly, timelines for these events are established. A sample Desktop Analysis is depicted in Fig. 1.

2) A Project Review survey: a primarily closed-ended survey of each project to systematically gather additional details not captured in the Desktop Analysis. The data from the surveys can be used to track research portfolio characteristics across projects over time.

For each GRDI project, we used these two tools and faceto-face discussions with the lead research project members to assess potential adoption and impact. This approach helped to validate our own understanding of the projects, maintain consistency in terminology and approach across projects, and minimize intrusions on the researcher's time.

\section{Summary Results}

As noted, all research outputs were classified into one of four output types: technology (e.g., tools, techniques, and methods); scientific knowledge (e.g., scientific databases and publications); capacity building (e.g., training and individual skill building); policy analysis (e.g., analyses of policies and reports). Scientific knowledge contributing to fundamental knowledge of Canadian forests was the most commonly expected type of output. The projects are also expected to have a number of shorter term technological benefits, including enhanced methodologies for the protection of Canadian forests from invasive species.

One reason for the expected realization of shorter-term benefits is the large number of collaborators and users directly involved in the projects. Projects often involved direct user-requests for specific outputs, close collaboration with research and operational institutions, and in-kind contributions from final users. This type of buy-in from end users ensures immediate relevance and use, but must be balanced with the goal of being applicable for broader audiences and the provision of larger aggregate impacts in the longer run. Without relevance to wider audiences, research projects may simply address the needs of a limited number of potential adopters.

Overall, GRDI project outputs are anticipated to generate a variety of impacts that align with the CFS and broader departmental priorities to promote forest sector competitiveness, advance environmental leadership, and optimize forest value. Across all projects, the impacts most commonly identified were primarily economic in nature, supporting the Canadian forest sector through improved organizational efficiency with respect to work practices and outputs (e.g., rapid development of improved tree stock) and reductions in risk to forest product market demand or supply (e.g., improved pest monitoring practices). Environmental impacts, where identified, primarily focused on forest health and were generally longer-term in nature. Social impacts that were identified were related to relationships associated with trade agreements.

For a more comprehensive discussion of the results, the full report can be obtained online at: https://cfs.nrcan. gc.ca/publications?id=38253 (English) and https://cfs.nrcan. gc.ca/publications?id=38254 (French).

\section{Final Comments}

Many researchers expressed that this process and way of thinking was useful to them. It helped provide a larger societal context for their research and a better understanding of pathways between intended project outputs and longer-term impacts. High-level information derived from these evaluations also helps quantify and summarize research patterns and portfolio investments.

Finally we note that cost-benefit analysis is also an important tool to assess the impacts of research (Davis et al. 2008). Such analyses are more typically performed 5-10 years after the research has been completed and require the development of defensible counterfactual narratives depicting the world with and without the research effort. Nevertheless, the results of the analyses performed here are already providing insights for future genomics-related research investments and the methods are being considered for other CFS research portfolios.

\section{Acknowledgements}

We would like to thank all of the GRDI project scientists that participated in the assessment process for their time and valuable feedback. We would also thank John Pedlar of the CFS for his comments and suggestions on an earlier draft of this manuscript.

\section{References}

Bartlett, A.G. 2016. The evolution and impacts of ACIAR's forestry research program over three decades. Aust. For. 79(3): 171-188. doi: 10.1080/00049158.2016.1184603.

Davis, J., J. Gordon, D. Pearce, D. Templeton. 2008. Guidelines for assessing the impacts of ACIAR's research activities. ACIAR Impact Assessment Series Report No. 58, Commonwealth of Australia: Canberra, Australia. $120 \mathrm{p}$.

Hope, E., D. Barsi, D. McKenney. 2017. Adoption and impact pathways for Canadian Forest Service genomics research and development initiative projects. Natural Resources Canada, Canadian Forest Service, Great Lakes Forestry Centre, Sault Ste Marie Ontario. Information Report GLC-X-18.

Isik, F. 2014. Genomic selection in forest tree breeding: The concept and an outlook to the future. New Forests. 45(3): 379-401. doi: 10.1007/s11056-014-9422-z.

Porth, I., G. Bull, S. Ahmed, Y.A. El-Kassaby, M. Boyland. 2015. Forest genomics research and development in Canada: Priorities for developing an economic framework. Forest. Chron. 91(1): 60-70. doi: $10.5558 / \mathrm{tfc} 2015-011$.

Prove the worth of basic research: agencies must show that basic research is worth the investment. 2016. Nature. 535:465. doi: $10.1038 / 535465 \mathrm{a}$.

Senate of Canada. 2016. Standing Committee on National Finance [online]. Ottawa. Wednesday, February $24^{\text {th, }} 2016$. Available from: https://sencanada.ca/en/Content/Sen/committee/421/nffn/52401-e [accessed 23 February 2017]. 